\title{
Critical role of androgen receptor level in prostate cancer cell resistance to new generation antiandrogen enzalutamide
}

\author{
Julia Hoefer ${ }^{1}$, Mohammady Akbor ${ }^{1,2}$, Florian Handle ${ }^{1}$, Philipp Ofer ${ }^{1}$, Martin Puhr ${ }^{1}$, \\ Walther Parson ${ }^{3,4}$, Zoran Culig ${ }^{1,5}$, Helmut Klocker ${ }^{1, *}$, Isabel Heidegger ${ }^{1, *}$ \\ ${ }^{1}$ Department of Urology, Division of Experimental Urology, Medical University of Innsbruck, Austria \\ ${ }^{2}$ School of Biosciences and Veterinary Medicine, University of Camerino, Camerino, Italy \\ ${ }^{3}$ Institute of Legal Medicine, Medical University of Innsbruck, Innsbruck, Austria \\ ${ }^{4}$ Forensic Science Program, The Pennsylvania State University, University Park, Pennsylvania, USA \\ ${ }^{5}$ Center of Biomolecular and Cellular Engineering, International Clinical Research Center, St. Anne's Hospital, Brno, Czech \\ Republic \\ *Equally contributing senior authors \\ Correspondence to: Helmut Klocker, email: helmut.klocker@i-med.ac.at \\ Keywords: prostate cancer, enzalutamide resistance, androgen receptor, AR-V7, AR gene amplification \\ Received: March 02, 2016 \\ Accepted: July 18, 2016 \\ Published: July 29, 2016
}

\section{ABSTRACT}

Enzalutamide is an androgen receptor (AR) inhibitor approved for therapy of metastatic castration resistant prostate cancer. However, clinical application revealed that $\mathbf{3 0}$ to $\mathbf{4 0} \%$ of patients acquire resistance after a short period of treatment. Currently, the molecular mechanisms underlying such resistances are not completely understood, partly due to a lack of model systems. In the present study we established three different cellular models of enzalutamide resistance including a cell line with wild type AR (LAPC4), DuCaP cells which overexpress wild-type AR, as well as a cell which has been adapted to long term androgen ablation (LNCaP AbI) and harbors the AR T878A mutation. After 10 months of cultivation, sustained growth in the presence of enzalutamide was achieved. When compared to controls, resistant cells exhibit significantly decreased sensitivity to enzalutamide as measured with ${ }^{3}[\mathrm{H}]$ thymidine incorporation and WST assay. Moreover, these cell models exhibit partly re-activated AR signaling despite presence of enzalutamide. In addition, we show that enzalutamide resistant cells are insensitive to bicalutamide but retain considerable sensitivity to abiraterone. Mechanistically, enzalutamide resistance was accompanied by increased AR and AR-V7 mRNA and protein expression as well as AR gene amplification, while no additional AR mutations have been identified.

\section{INTRODUCTION}

Enzalutamide (Xtandi $($ ) is an oral androgen receptor (AR) inhibitor which has been developed for the treatment of prostate cancer (PCa). Enzalutamide blocks binding of androgens to AR, nuclear translocation of AR as well as AR-mediated DNA binding [1]. According to the literature, enzalutamide lacks partial agonistic activity which has been described for its predecessor bicalutamide [2]. After proving its efficacy in preclinical models [1], a large Phase III study (AFFIRM), in which overall survival increased from 13.6 to 18.4 months, demonstrated its benefit in the treatment of metastatic castration resistant prostate cancer (mCRPC) in patients post chemotherapy and the drug was finally approved in 2013 [3]. A followup study (PREVAIL) evaluating enzalutamide in mCRPC patients before chemotherapy confirmed increased overall survival in enzalutamide treated patients (from 30.2 to 32.4 months), leading to clinical registration also in the pre-chemotherapy setting [4].

Despite obvious benefits, application of the drug in a clinical setting revealed that not all patients respond to new generation AR modulators including enzalutamide [5]. Numerous patients show endogenous resistance 
to the drug. Moreover, a considerable proportion of patients develop resistance during treatment, leading to biochemical or symptomatic recurrence after a short period of regression. Thus, identification of biomarkers which allow distinguishing patients who are likely to respond to enzalutamide from those who will not benefit from the drug is urgently needed. In addition, it is essential to develop new therapy strategies and to address the challenging question of how currently available drugs should be ideally sequenced in order to prevent or overcome the occurrence of resistances. These aims require the availability of different cellular models of enzalutamide resistance which allow for detailed analysis of the underlying mechanisms. There is evidence that AR splice variants such as the AR splice variant 7 (ARV7) [6] or point mutations in the DNA regions encoding for the ligand binding domain of AR [7] are involved in enzalutamide resistance. However, until now the molecular mechanisms underlying an endogenous or acquired insensitivity to enzalutamide are not completely clarified, in part due to a lack of cellular models which are essential for detailed analysis of molecular changes that occur during enzalutamide therapy.
In the present study we aimed to uncover a potential involvement of AR expression in enzalutamide resistance. We established three different cellular models of enzalutamide resistance including a cell line with wild type AR (LAPC4), a cell line overexpressing wild-type $\mathrm{AR}(\mathrm{DuCaP})$ as well as a cell line (LNCaP Abl) which has been generated by long term androgen ablation from LNCaP, which harbor a mutated AR (T878A) [8, 9]. Using these cell lines, we investigated potential changes in the AR gene, mRNA and protein expression.

\section{RESULTS}

\section{Generation of enzalutamide resistant cell lines}

To define a starting concentration of enzalutamide for the generation of resistant cell lines, we treated LAPC4 cells with increasing concentrations of the drug $(0.1 \mu \mathrm{M}-10 \mu \mathrm{M})$ and measured expression of AR target genes FKBP5 and PSA. As shown in Figure 1A, enzalutamide inhibited AR signaling dose dependently after 48 hours (IC50: $0.18 \mu \mathrm{M}$ and $0.14 \mu \mathrm{M}$ for PSA
A

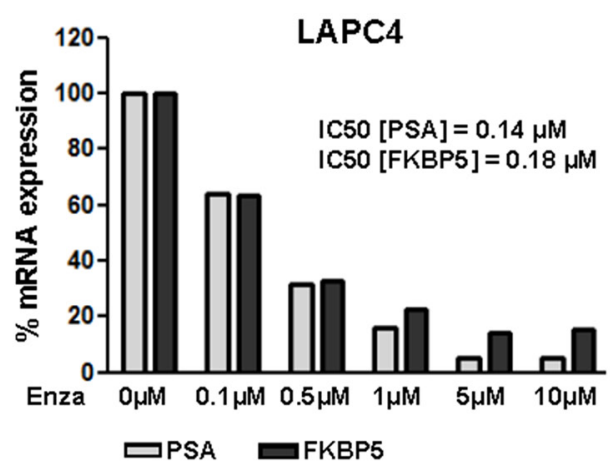

C

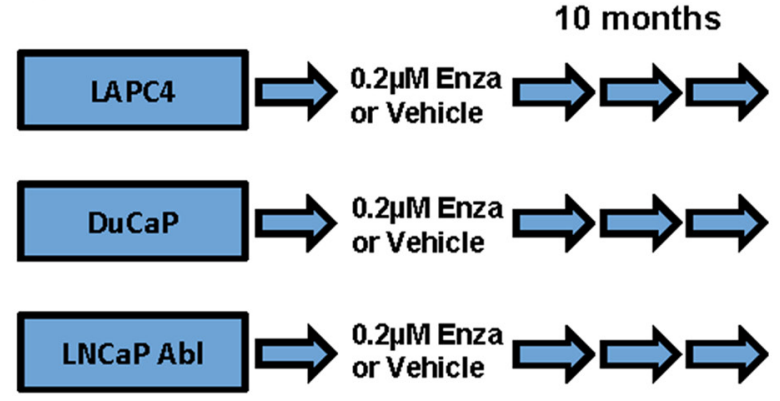

B

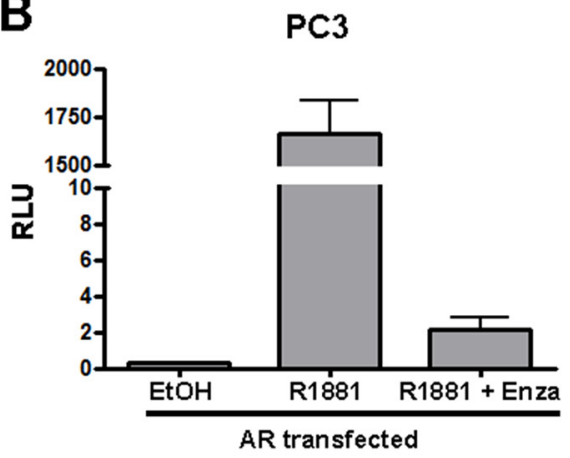

2 months

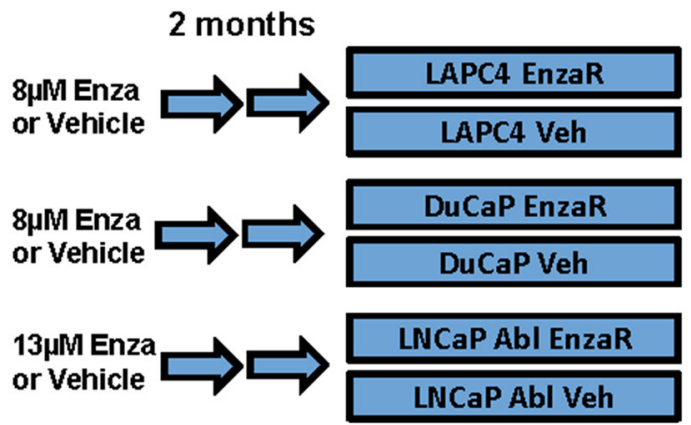

Figure 1: Generation of enzalutamide resistant cell lines. A. LAPC4 cells were cultured in RPMI $+1 \mathrm{nM}$ DHT and treated with increasing concentrations of enzalutamide for $48 \mathrm{~h}$. mRNA expression of AR target genes PSA and FKBP5 was analyzed using RT-qPCR. B. AR reporter gene assay after treatment with R1881 [1 nM] or enzalutamide $[10 \mu \mathrm{M}]$ or both was performed with PC-3 cells ectopically expressing AR, androgen responsive elements and a TATA-box in framework of nanoluc reporter vector was measured by Nano-Glo Dual-Luciferase Assay and normalized to control luciferase activity $\mathbf{C}$. Treatment scheme for the generation of enzalutamide resistant cell lines. LAPC4, DuCaP and LNCaP abl were cultured in the presence of increasing doses of enzalutamide or vehicle (EtOH) for 10 months (approximately 50 passages) until the final concentrations ( $8 \mu \mathrm{M}$ for LAPC4 and DuCaP, $13 \mu \mathrm{M}$ for LNCaP Abl) were reached. Cell lines were further cultured for 2 months in the presence of the final enzalutamide concentrations. 
and FKBP5, respectively). Moreover, enzalutamide successfully inhibited reporter gene activity after treatment with the synthetic androgen R1881 (Figure 1B). On the basis of these results, we started to culture DuCaP, LAPC4 and LNCaP Abl parental cell lines in the presence of $0.2 \mu \mathrm{M}$ enzalutamide or vehicle $(\mathrm{EtOH})$ in order to generate enzalutamide resistant and vehicle control subcell lines, respectively. Enzalutamide concentration was incrementally increased up to a final concentration of 8 $\mu \mathrm{M}$ (DuCaP, LAPC4). Due to the fact that LNCaP abl cells are already adapted to growth in androgen ablated conditions, these cells were less sensitive and did not exhibit significant cell death or growth arrest up to a concentration of $10 \mu \mathrm{M}$ enzalutamide. We therefore increased the final concentration for LNCaP abl EnzaR to $13 \mu \mathrm{M}$. After 10 months, control and resistant cells showed comparable growth behavior in the presence of the final concentrations of vehicle or enzalutamide, respectively. To ensure sustained survival and growth, cells were kept in these conditions for another 2 months. A schematic overview of the procedure is presented in Figure 1C.

\section{Newly generated sub-cell lines show decreased sensitivity to enzalutamide}

After one year of cultivation, enzalutamide resistant (EnzaR) and vehicle treated (Veh) cell lines exhibit a comparable morphology (Figure 2A). In order to evaluate the degree of resistance of long term enzalutamide-treated cell lines, we measured viability using WST assay as well as proliferation by ${ }^{[3]} \mathrm{H}$ thymidine incorporation assay following treatment with different doses of vehicle or enzalutamide. Given the expected insensitivity of the EnzaR sub cell-lines, enzalutamide doses above the starting concentration of the selection process were selected (3-10 $\mu \mathrm{M}$ for LAPC4, DuCaP or 5-15 $\mu \mathrm{M}$ for LNCaP Abl). As expected, in all three control (vehicle) cell lines we observed maximal inhibition of proliferation (Figure 2B) and viability (Figure 2C) already after treatment with the lowest enzalutamide concentration. With respect to viability, LAPC4 exhibited higher sensitivity to enzalutamide than DuCaP or LNCaP Abl cells. Notably, all three enzalutamide resistant sub-lines exhibit significantly decreased sensitivity to the drug up to $10 \mu \mathrm{M}$. Of note, in the resistant LAPC4 (LAPC4 EnzaR) sub-line we observed even a significant increase in proliferation and viability in the presence of enzalutamide, when compared to vehicle treated controls (Figure 2B and 2C). Measurement of the expression of AR target genes FKBP5, KLK2 and PSA revealed that resistant sub cell-lines regain active AR signaling despite presence of enzalutamide, although target gene expression patterns revealed some cell type and gene specific heterogeneity (Supplementary Figure S1). Of the three target genes,
FKBP5 was not upregulated in LAPC4 cells, neither was KLK2 in LNCaP abl cells.

\section{Enzalutamide resistant sub-cell lines are partly sensitive to abiraterone but insensitive to bicalutamide}

Next, we aimed to evaluate possible crossresistances of the newly generated enzalutamide resistant cell lines with other drugs that target the AR pathway, such as bicalutamide or abiraterone. Briefly, bicalutamide is an older, non-steroidal anti-androgen which is clinically still used as an adjuvant agent in patients receiving radiation therapy due to intermediate or high risk PCa. Moreover, bicalutamide prevents the flare up phenomena in LHRH agonist therapy [10]. Abiraterone on the other hand, blocks biosynthesis of androgens by inhibition of CYP17A1, however, it has been suggested that it may in addition act as direct AR antagonist [11]. As enzalutamide, also abiraterone is approved for the treatment of mCRPC before or after chemotherapy. Interestingly, cross resistance of enzalutamide resistant PC $346 \mathrm{C}$ cells to abiraterone has been reported in 2013 [12]. Thus, we assessed the degree of sensitivity of the newly generated enzalutamide resistant DuCaP, LAPC4 and LNCaP Abl sub-cell lines to abiraterone and bicalutamide. Our data clearly show that abiraterone is still significantly decreasing proliferation in all three and viability in two of three sub-lines, although the growth-inhibitory effect of abiraterone was reduced in LAPC4 and LNCaP Abl EnzaR compared to vehicle controls (Figure 3A and 3B). These findings indicate a potential therapeutic benefit of applying abiraterone to patients who relapsed after enzalutamide.

While we observed complete resistance to bicalutamide in both DuCaP sub-cell lines, LAPC4 and $\mathrm{LNCaP}$ Abl control cell lines are responsive to the drug. Notably, we detected decreased bicalutamide sensitivity in LNCaP Abl EnzaR compared to controls while LAPC4 EnzaR not only lost their sensitivity to bicalutamide, but exhibited even enhanced proliferation in the presence of the drug (Figure 3A). Measurement of viability under the same conditions yielded similar results (Figure 3B).

\section{Development of enzalutamide resistance is not caused by a gain of AR mutations}

In order to uncover the mechanisms leading to enzalutamide resistance, we first hypothesized that mutations in the AR gene may lead to decreased sensitivity to the drug. However, sequencing of AR coding cDNA revealed that LAPC4 and DuCaP EnzaR sub-lines did not gain any AR mutations compared to the vehicle treated controls. Similarly, LNCaP Abl EnzaR did not harbor additional AR mutations other than the known LNCaP mutation T878A $[8,9]$. 
A

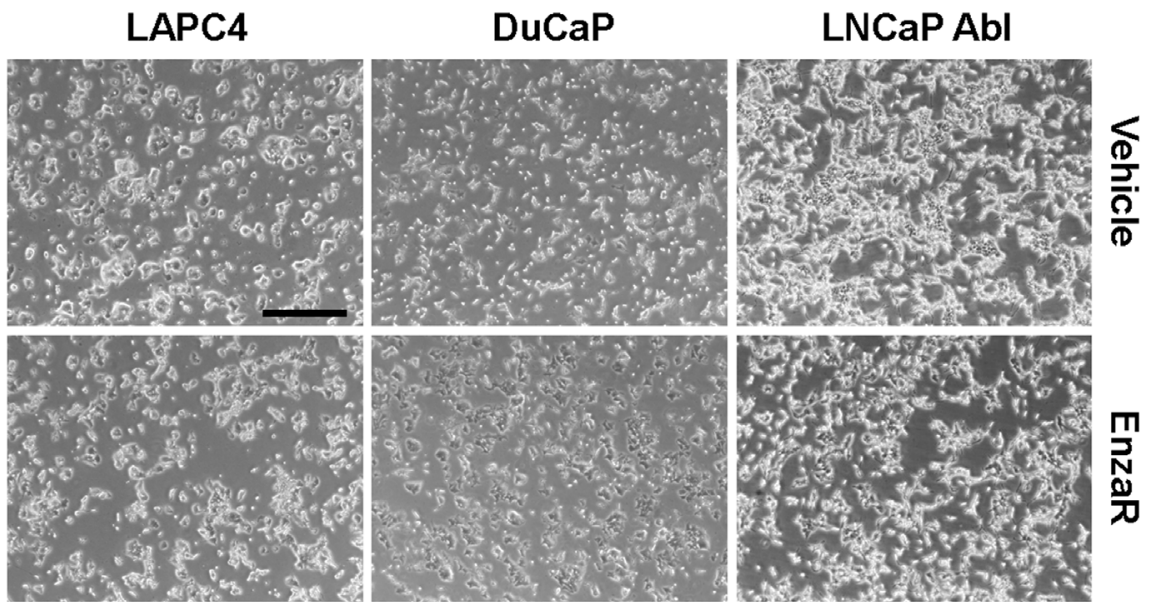

B

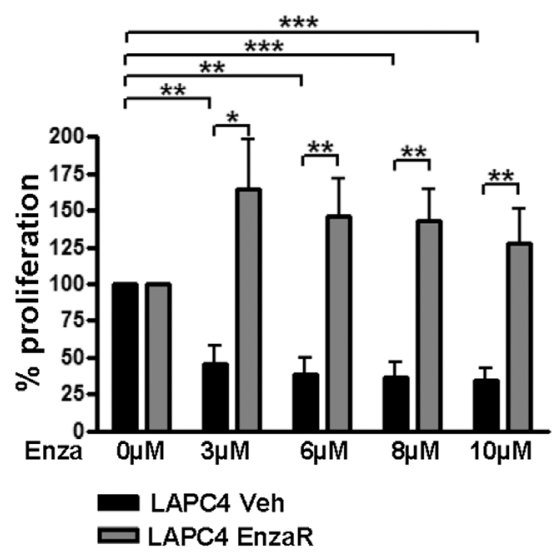

C

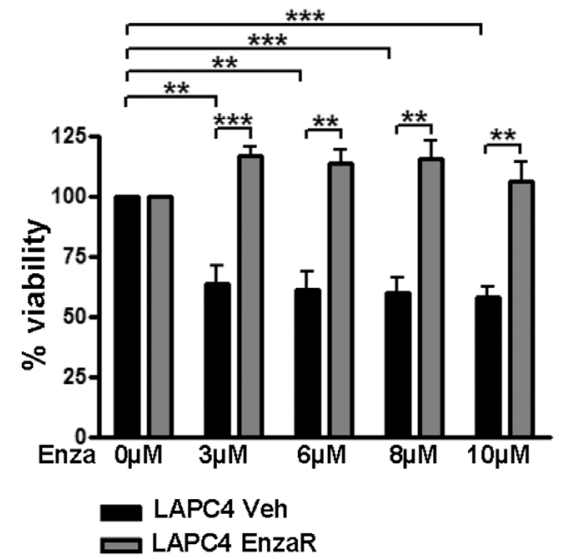

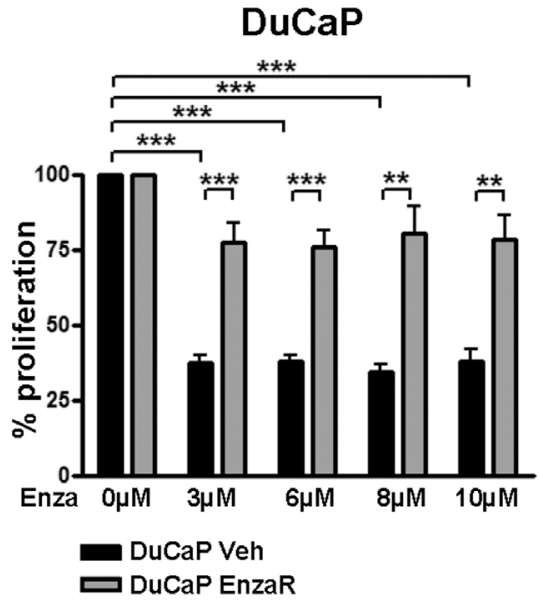

DuCaP

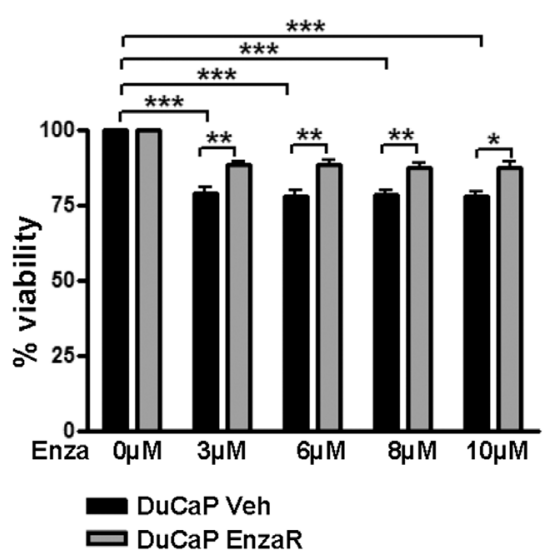

LNCaP Abl

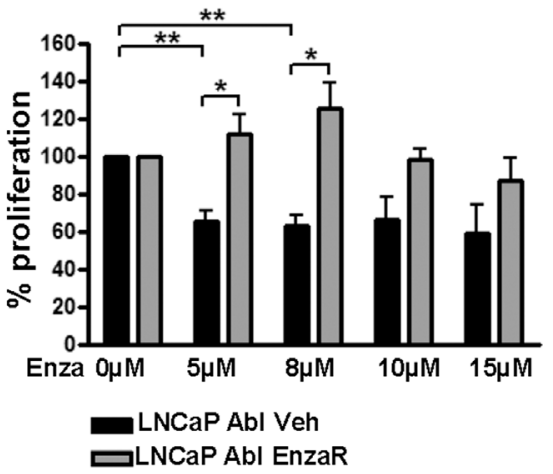

\section{LNCaP Abl}

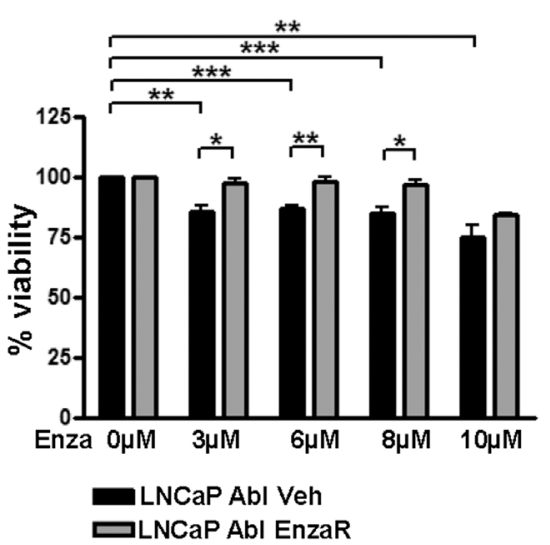

Figure 2: Enzalutamide resistant cell lines exhibit decreased sensitivity to enzalutamide. A. Representative images of vehicle and EnzaR cell lines were taken after 12 months of culturing. 4x objective. Scalebar: $500 \mu \mathrm{m}$. B, C. Determination of the degree of enzalutamide resistance. Proliferation (B) and viability (C) in DuCaP, LAPC4 and LNCaP Abl vehicle and enzalutamide resistant cell lines after 6 days of exposure to different concentrations of enzalutamide were measured by ${ }^{3}[\mathrm{H}]$ thymidine incorporation assay and WST assay, respectively. Ethanol was used as control. Data represent mean + SEM from at least 3 independent experiments. $* ; p=<0.05$. **;p=<0.01. $* * * ; p=<0.001$ 
Enzalutamide resistance is accompanied by increased expression of full length $A R$ and $A R$ variant 7

Since we did not identify additional AR mutations which account for development of enzalutamide resistance, we next assessed AR expression level in vehicle or EnzaR sub-cell lines. AR mRNA significantly increased in LAPC4 and DuCaP EnzaR cells, while in LNCaP Abl EnzaR we did not observe major changes in AR mRNA expression (Figure 4A). Similarly, AR full length protein was highly elevated in enzalutamide resistant LAPC4 and DuCaP cells. LNCaP Abl EnzaR exhibit only a slight increase in full length AR expression (Figure 4B). Short term treatment (14 days) of LAPC4 vehicle cells with $8 \mu \mathrm{M}$ enzalutamide (Figure $4 \mathrm{C}$ ) clearly demonstrated that AR overexpression is not a short term effect of drug treatment but develops as a long term adaptation during acquisition of resistance. It has been suggested that presence of a truncated AR variant (AR-V7) is associated with resistance to enzalutamide [13]. Thus, we assessed AR-V7 mRNA and protein levels in the newly generated EnzaR sub cell-lines. As shown in Figure 4D, LAPC4 cells which per se do not exhibit relevant levels of $\mathrm{V} 7 \mathrm{mRNA}$ or protein, acquired $\mathrm{V} 7 \mathrm{mRNA}$ and protein expression with development of enzalutamide resistance. In $\mathrm{DuCaP}$ on the other hand, V7 was present even in the control cell line and further increased in DuCaP EnzaR. In contrast, neither LNCaP Abl vehicle nor EnzaR exhibited detectable amounts of truncated AR variants (Figure 4D).

Changes in AR expression in enzalutamide resistant cells were further confirmed by immunofluorescence (Figure 5). In the LAPC4 vehicle cells, AR staining was weak under serum starvation conditions $(10 \%$ SF) and increased after R1881 treatment. As expected, enzalutamide inhibited basal expression as well as R1881 driven AR upregulation. In LAPC4 EnzaR on the other hand, AR was elevated already under serum starvation and did not significantly change upon R1881 addition. Notably, presence of enzalutamide further increased nuclear AR, both in the absence and presence of R1881 (Figure 5). A similar situation was found in DuCaP cell lines (Supplementary Figure S2).

\section{AR gene amplification is one mechanism of increased AR expression in enzalutamide resistant cells}

In order to further uncover the molecular background underlying increased AR expression in
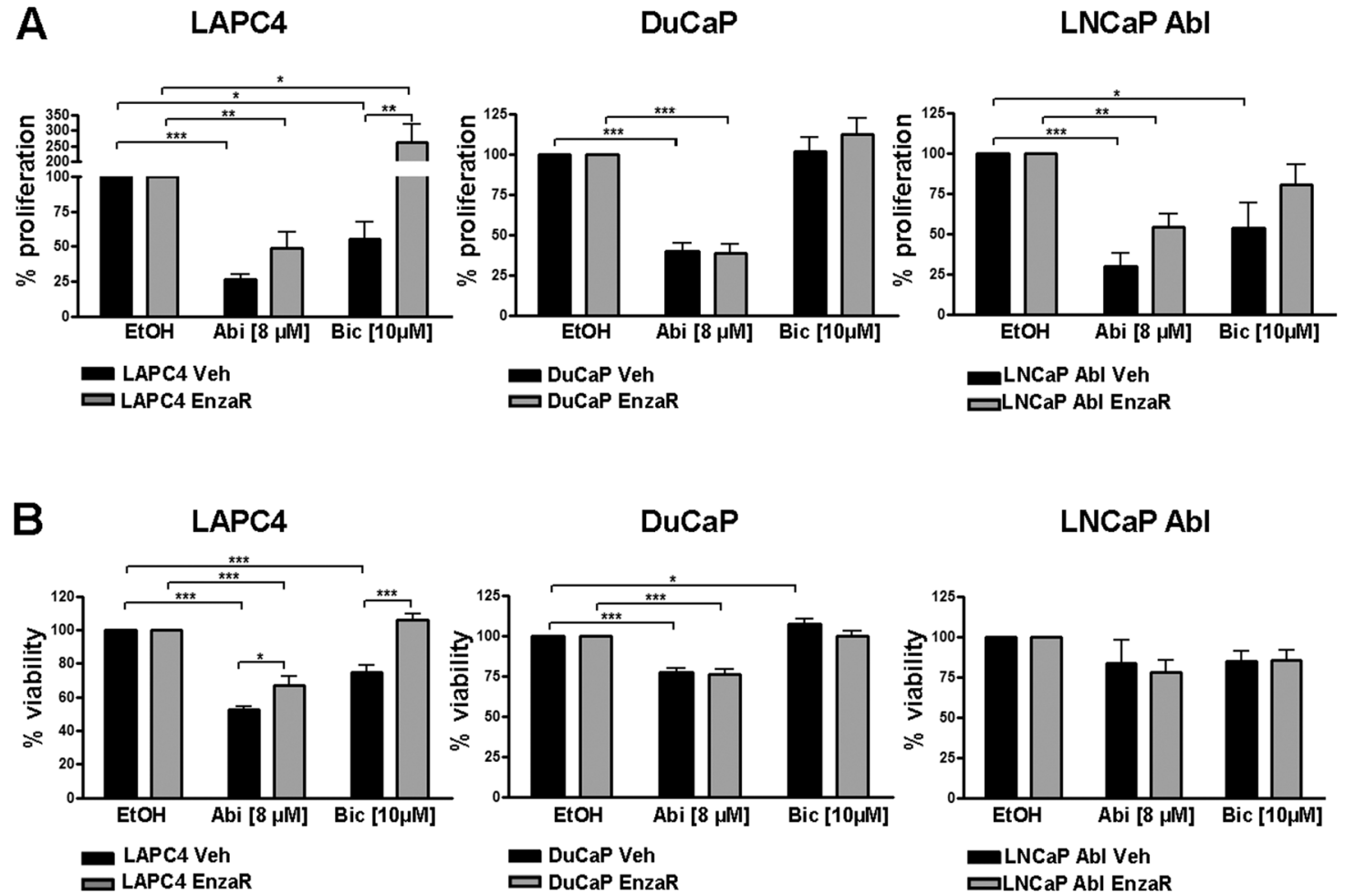

Figure 3: Determination of possible cross resistances of enzalutamide resistant cell lines with abiraterone or bicalutamide. Proliferation A. and viability B. in DuCaP, LAPC4 and LNCaP Abl vehicle and enzalutamide resistant cell lines after 6 days of exposure to $8 \mu \mathrm{M}$ abiraterone or $10 \mu \mathrm{M}$ bicalutamide was measured by ${ }^{3}[\mathrm{H}]$ thymidine incorporation assay and WST assay, respectively. Ethanol was used as control. Data represent mean + SEM from at least 3 independent experiments. $* ; p=<0.05$. $* * ; p=<0.01$. $* * * ; p=<0.001$ 
enzalutamide resistant cells, we investigated AR gene copy number in all established vehicle or EnzaR sub-cell lines. As an additional control, we included corresponding parental cells which had been frozen before long term treatments were started. AR gene amplification was determined by duplex qPCR of genomic DNA amplifying an AR Exon 1 fragment (Chr Xq12) in relation to a POLG Exon 3 fragment (Chr 15q25). AR/POLG copy number ratios were calculated as fold change of normal male DNA which harbors 1 copy of AR. As expected, parental as well as vehicle treated LAPC4 cells exhibit a normal AR copy number. Strikingly, we detected a $\sim 8$-fold amplification of AR gene in enzalutamide resistant LAPC4 (Figure 6A) which was gained gradually over time during passaging with increasing doses of enzalutamide (Figure 6B). Parental and vehicle-treated DuCaP cells on the other
A

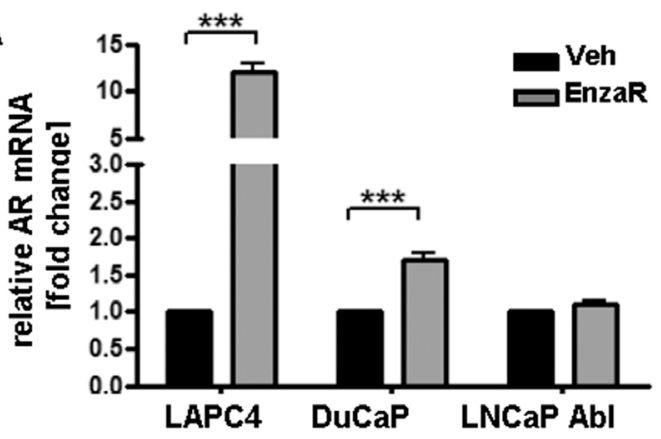

C

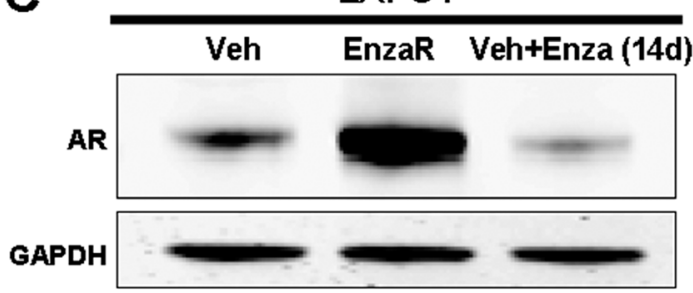

B
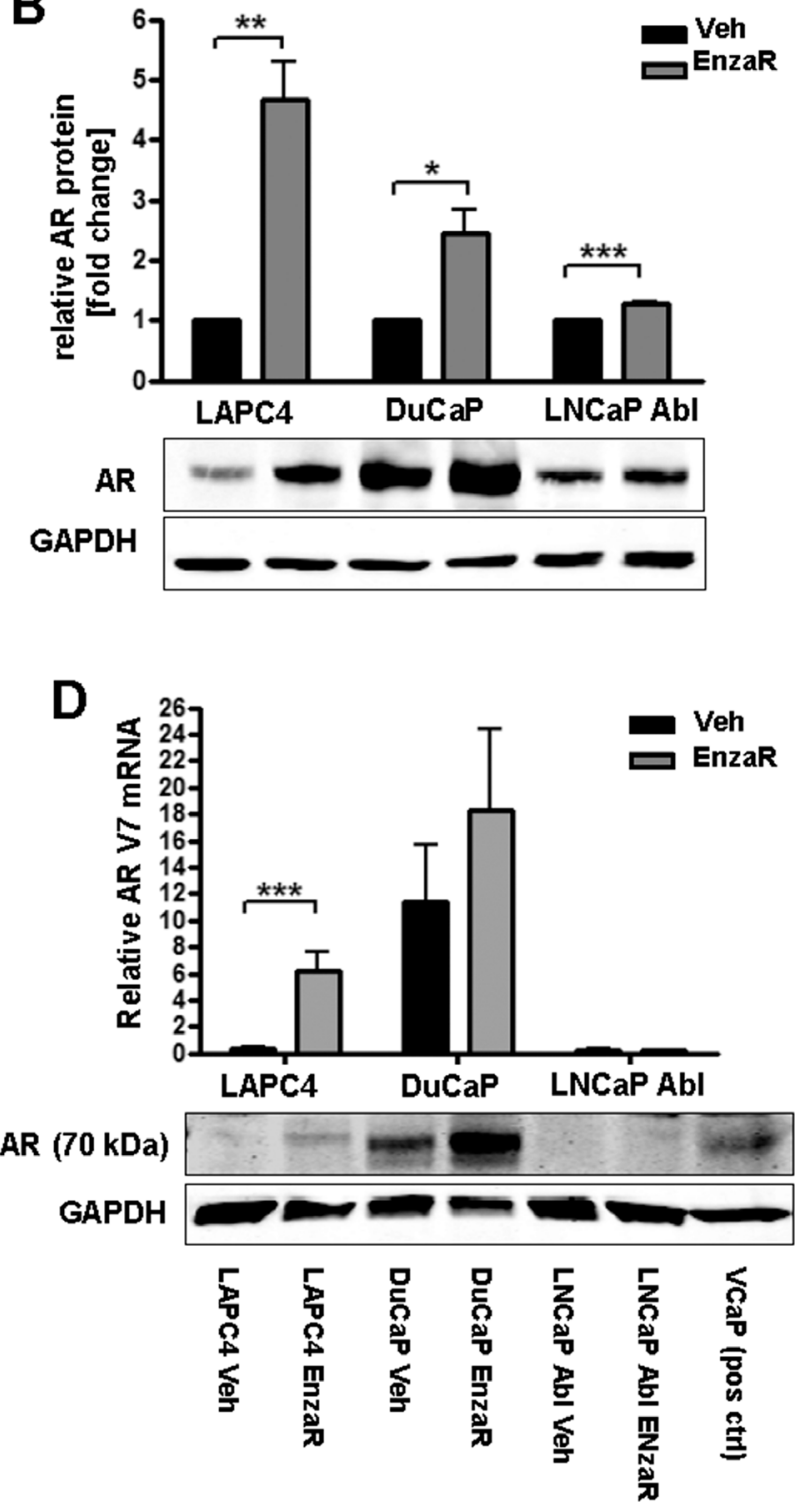

Figure 4: Enzalutamide resistant cell lines exhibit increased AR expression. A. AR mRNA expression was assessed by qRTPCR. Data represent mean + SEM from 4 independent experiments. ${ }^{*} ; \mathrm{p}=<0.05$. ${ }^{* *} ; \mathrm{p}=<0.01 .{ }^{* * *} ; \mathrm{p}=<0.001$. B. Statistical analyses and representative Western blot images of full length AR protein expression. Data represent mean $+\mathrm{SEM}$ from 3 independent experiments. $* ; \mathrm{p}=<0.05 . * * ; \mathrm{p}=<0.01 .{ }^{* * * ; p=<0.001 . ~ C . ~ W e s t e r n ~ b l o t ~ o f ~ L A P C 4 ~ V e h ~ a n d ~ L A P C 4 ~ E n z a R, ~ a s ~ w e l l ~ a s ~ i n ~ L A P C 4 ~ v e h i c l e ~ c e l l s ~ w h i c h ~ w e r e ~}$ treated for 2 weeks with enzalutamide $[8 \mu \mathrm{M}]$. D. Upper panel: Statistical analysis of AR-V7 mRNA expression. Data represent mean + SEM from 4 independent experiments. $* ; p=<0.05 . * * ; p=<0.01 .{ }^{* * *} ; \mathrm{p}=<0.001$. Lower panel:Representative Western blot image of AR variant observed at $70 \mathrm{kd}$ size (V7). First lane represents Marker band the $75 \mathrm{kDa}$ size. Last lane represents VCaP lysate as positive control for V7 expression. 
hand already exhibited a dramatic amplification of the AR locus ( $~ 80$ copies) which was not further changed after long term treatment with the drug. Similarly, enzalutamide treatment did not influence the normal AR copy number in LNCaP Abl cells (Figure 6A).

\section{DISCUSSION}

The AR is one of the major drivers of PCa progression and various changes in AR status such as AR amplifications or mutations lead to persistence of AR signaling in CRPC [14]. Therefore, numerous therapeutic approaches for advanced or castration resistant $\mathrm{PCa}$ target the androgen - AR signaling cascade. The new generation AR inhibitor enzalutamide has been shown to increase overall survival and suppress disease related symptoms when administered to mCRPC patients before or after chemotherapy. Despite of this, many patients do not respond to enzalutamide therapy or acquire resistance during treatment. It has been proposed that AR mutations or changes in AR expression might contribute to such insensitivities. However, until now the underlying

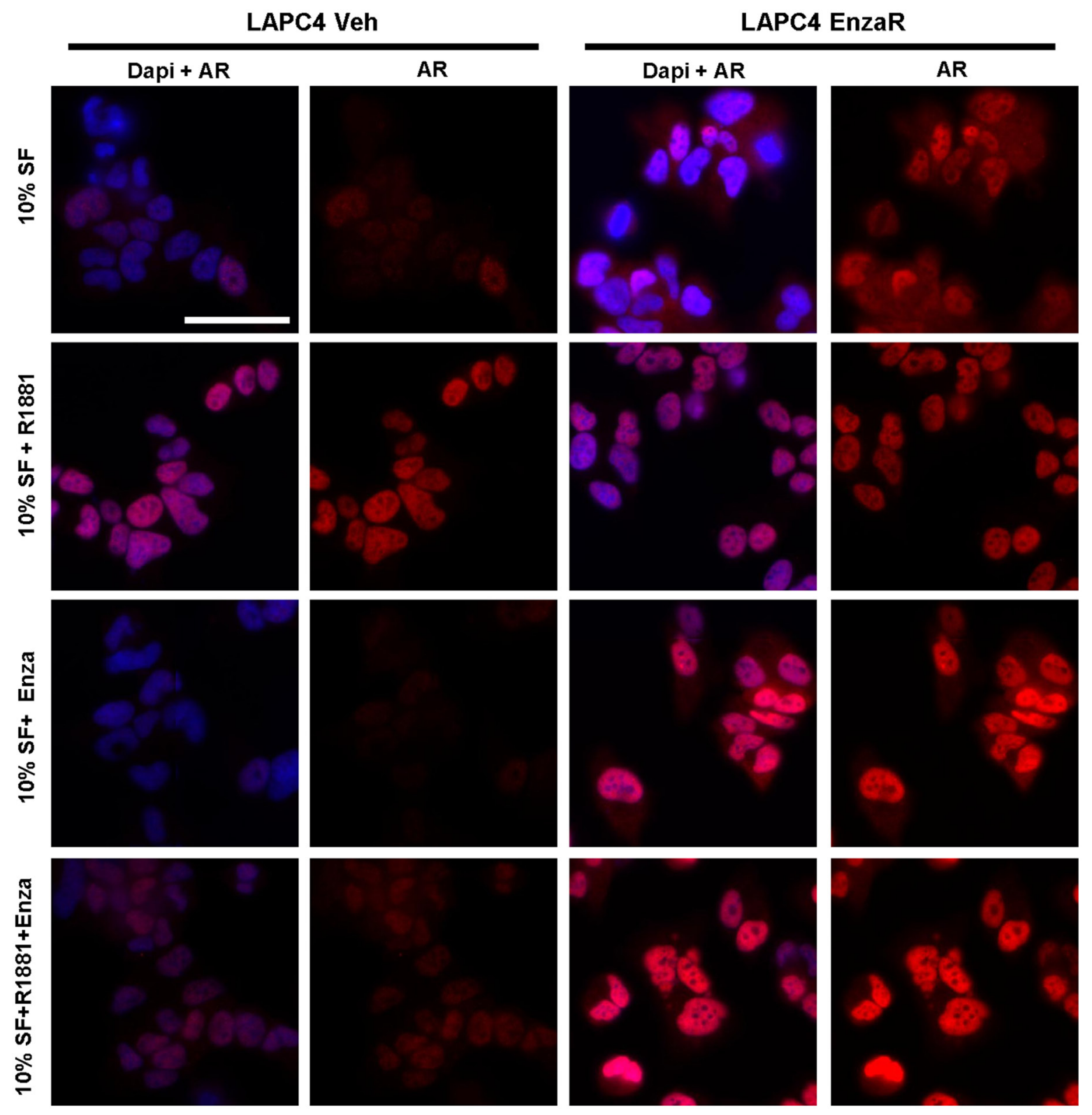

Figure 5: Immunofluorescence staining of vehicle or enzalutamide resistant LAPC4 cells. Cells were cultured in medium containing 10\% charcoal stripped FBS (SF), supplemented with vehicle (EtOH), $1 \mathrm{nM} \mathrm{R} 1881$, or $8 \mu \mathrm{M}$ enzalutamide as indicated. AR was detected using mouse anti AR (Biogenex) and visualized using AlexaFluor 488 donkey anti mouse secondary antibody. Nuclei were counterstained with DAPI. Magnification: 40x. Scalebar: $50 \mu \mathrm{m}$. 
mechanisms are not completely uncovered, in part due to a lack of appropriate models which would allow for detailed analysis. In the present study, we describe the cultivation and characterization of three enzalutamide resistant cell lines with different AR statuses. LAPC4 cells represent metastatic PCa cells with moderate levels of wild type AR. Moreover, we included LNCaP Abl cells, a LNCaP sub-line which has been grown in the absence of androgens for 60 passages [15]. These cells are androgen independent but -sensitive, thus representing a CRPC model [15]. LNCaP abl as well as the parental LNCaP harbor the T878A (formerly T877) AR mutation [16] which lies in the LBD of AR and is the most frequently reported substitution in prostate cancer [17]. DuCaP on the other hand, overexpress full length AR due to gene amplification as shown by us and others [18] and are in addition positive for AR-V7 splice variant, a variant which is frequently detected in patients resistant to abiraterone and enzalutamide therapy [19]. The newly generated enzalutamide resistant cell lines thus represent useful models for analysis of resistance mechanisms in cells with distinct AR statuses, reflecting heterogeneity in PCa patients.

Reviewing the literature, several possible mechanisms of enzalutamide resistance are discussed including AR splice variants, mutations or amplifications. One study showed that enzalutamide treatment of LNCaP causes selection of a F876L missense mutation in the AR ligand binding domain which leads to partial agonism and thus resistance to the drug [7]. However, in our study development of enzalutamide resistance in the used cell lines was not accompanied by the appearance
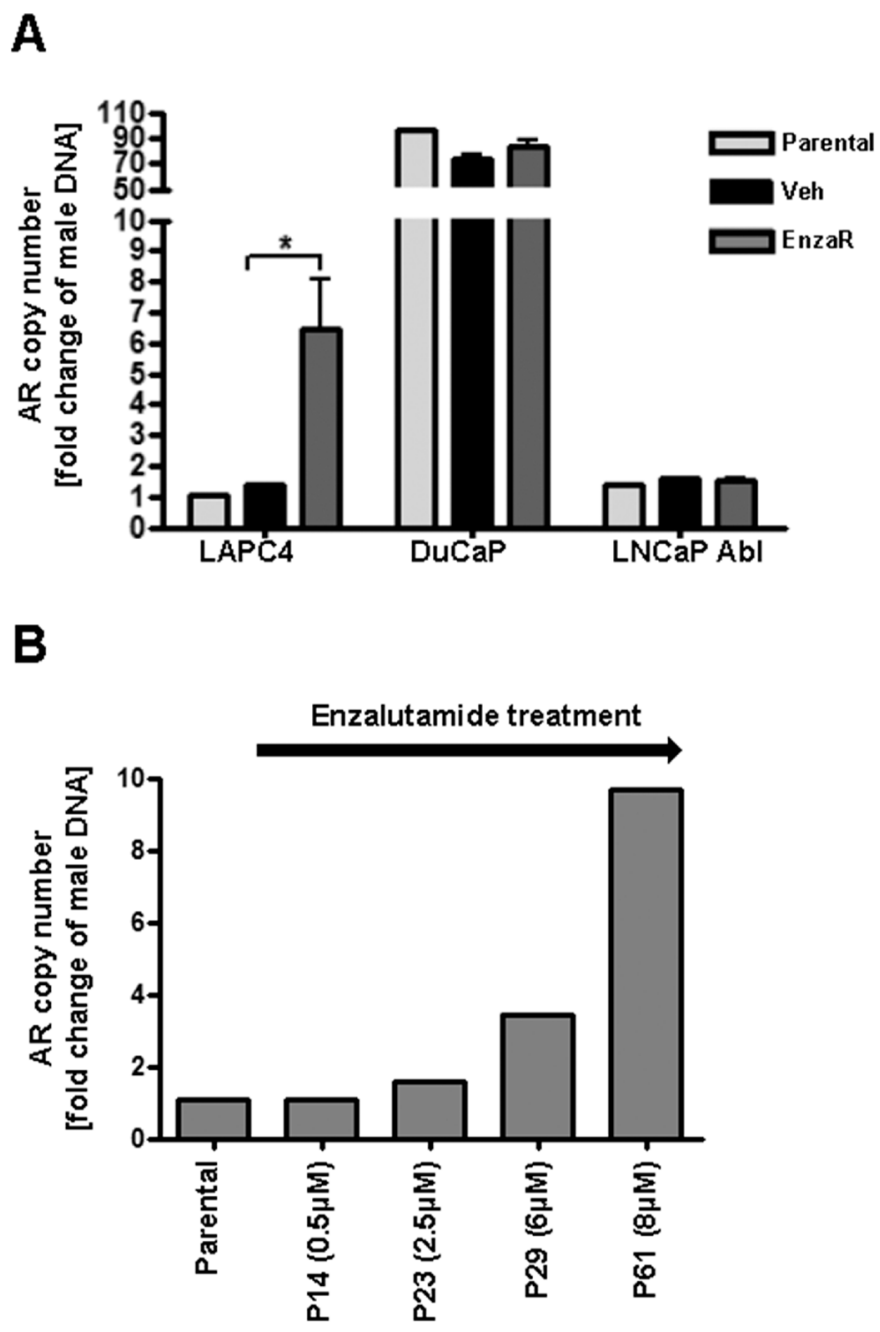

Figure 6: Enzalutamide resistant LAPC4 acquired AR gene amplification. A. AR gene amplification was determined by duplex qPCR of genomic DNA amplifying an AR Exon 1 fragment (Chr Xq12) in relation a POLG Exon 3 fragment (Chr 15q25). AR/ POLG copy number ratios were calculated as fold change of normal male DNA which harbors 1 copy of AR. Data represent mean +SEM from 3 independent PCR analyses. *; $p=<0.05$ B. Analysis of AR gene amplification over time during generation of enzalutamide resistant LAPC4 cells starting from parental LAPC4. $\mathrm{P}=$ Passage. 
of new AR mutations. This is not surprising, considering that the overall frequency of somatic AR mutations in CRPC patients is less than $10 \%[20,21]$. Moreover, the experimental procedure to generate enzalutamide resistant LNCaP in the study mentioned above [7] was different from our protocol. In the present study, we were able to show significantly increased AR mRNA and protein levels in 2 out of 3 enzalutamide resistant sub-lines, suggesting AR overexpression as a common mechanism for enzalutamide resistance. This is in line with findings from Yamamoto et al. who detected high levels of fulllength $\mathrm{AR}$ and $\mathrm{AR}$ variants in enzalutamide resistant LNCaP [22]. However, the underlying mechanisms causing AR overexpression seem to be diverse among different cell lines. In LAPC4 cells which have a normal AR copy number and express moderate levels of wild type $\mathrm{AR}$, long term enzalutamide treatment results in step-wise AR gene amplification and consequently in increased AR mRNA (10-fold) and protein (5-fold) levels. In line with this, it has been reported that AR amplifications are rare in untreated tumors but occur at a higher frequency in cases of endocrine therapy failure [23] indicating an important role for AR gene amplification in hormone therapy response. Indeed, one study suggested that AR amplification in patients after enzalutamide treatment correlates with resistance to the drug [24] and a very recent report showed that AR copy number gain occurs in 36\% of patients after enzalutamide therapy and is associated with decreased progression free and overall survival [25]. In the present study we show that DuCaP exhibit a $\sim 60$ fold AR gene amplification which results in high AR protein levels already in the parental cell line. Although no further amplification of the AR gene was present in DuCaP EnzaR, we detected a significant increase in both, AR mRNA (3-fold) and protein (2.5-fold), which is hence caused by other mechanisms than gene amplification. In this context it has to be stated that $\mathrm{AR}$ is upregulated in most cases of CRPC but only in one third of cases this could be attributed to AR gene amplification [23]. These findings clearly demonstrate involvement of other mechanisms of AR upregulation, such as enhanced AR transcription or stabilization [26].

Recently, it has been shown that presence of AR splice variant 7 (ARV7) in bone marrow biopsies from patients under enzalutamide therapy was associated with insensitivity to the drug [27]. In addition, Antonarakis et al. found lower response rates and shorter progression free survival in enzalutamide treated patients with detectable amounts of V7 in circulating tumor cells [13]. In line with these findings, we were able to confirm increased expression of a $70 \mathrm{kDa} A R$ variant in 2 out of 3 enzalutamide resistant sub-lines. Moreover, our data prove that V7 is expressed at low levels already in parental DuCaP cells. We hypothesize that presence of V7 in this cell line, together with amplification of the AR gene, may explain the observed general insensitivity of DuCaP to bicalutamide, and a lower sensitivity to enzalutamide compared to LAPC4. Taken together, these results strongly suggest a role for AR-V7 in the development of enzalutamide resistance. Thus, it might be worthwhile to therapeutically inhibit AR variant expression in order to overcome enzalutamide resistance. In this context, one study already showed that the antihelminthic drug niclosamide is able to potently block AR-V7 expression and consequently $\mathrm{PCa}$ cell growth in enzalutamide sensitive and resistant cells [28].

Given that in enzalutamide resistant LNCaP Abl cells we did not detect relevant changes in AR full length or V7 levels, we conclude that also other molecules apart from the AR may be involved in enzalutamide resistance. In this context, it has been shown that enzalutamide induces autophagy in CRPC cell lines by AMPK activation and mTOR suppression [29]. In addition, it has been demonstrated that constitutively active STAT3 is accompanied with resistance to enzalutamide [30]. Most interestingly, Arora et al. showed that induction of glucocorticoid receptor (GR) expression is frequently found in enzalutamide resistant tumors and propose that in the presence of enzalutamide the GR may substitute for AR, by activating a certain subset of AR target genes, thereby promoting $\mathrm{PCa}$ progression [31]. Indeed, we show here that in LNCaP Abl EnzaR cells, KLK2 mRNA expression is dramatically decreased while no change in PSA and FKBP5 was detected (Supplementary Figure S1). Thus, future studies might assess the role of GR in LNCaP Abl EnzaR cells.

Van Soest et al. showed that enzalutamide resistant PC346C cells exhibit an almost complete cross resistance to abiraterone [12] which may be a cell line specific observation. Here, we demonstrate that enzalutamide resistant $\mathrm{LAPC} 4, \mathrm{DuCaP}$ and $\mathrm{LNCaP} \mathrm{Abl}$ are partly sensitive to $8 \mu \mathrm{M}$ abiraterone even though the degree of sensitivity was diminished in enzalutamide resistant LAPC4 and LNCaP Abl when compared to control cells. Of note, parental and enzalutamide resistant DuCaP exhibit comparable sensitivity to abiraterone, despite presence of AR-V7. This result may be explained by a study from Pfeiffer et al. who described an intracrine androgen synthesis in DuCaP cells which is further increased upon long term androgen depletion [32], indicating that both parental and long-term enzalutamide treated DuCaP cells rely at least to a certain degree on steroidogenesis, which renders them sensitive to abiraterone treatment. In summary, findings from us and others indicate that abiraterone might be beneficial at least in a subset of patients relapsing after enzalutamide treatment. In line with this hypothesis, there are two small clinical studies showing that abiraterone still exhibits modest overall activity in MCRPC patients who relapsed after enzalutamide, with large heterogeneity in the degree of response among different patients. Loriot et al. observed a $\geq 50 \%$ or $\geq 30 \%$ PSA drop upon abiraterone in $8 \%$ or $18 \%$ 
of patients who previously relapsed under enzalutamide treatment [33]. In a second study, Noonan et al. found $\geq 50 \%$ or $\geq 30 \%$ PSA decline upon abiraterone in $3 \%$ or $11 \%$ of patients pretreated with enzalutamide, respectively [34]. These studies and our own results underline the heterogeneity of prostate tumors regarding AR signaling addiction and resistance mechanisms and suggest that a subset of patients may benefit from abiraterone after enzalutamide failure. Considering the fact that for patients with metastatic CRPC therapy sequence still remains speculative with great differences in outcome (reviewed in [35]), it will be of importance to verify these clinical findings in larger patient cohorts with such a treatment sequence. Moreover, it has to be noted that in this study we only tested effects of a single abiraterone concentration $(8 \mu \mathrm{M})$ at a single time point in the EnzaR sub-lines. Detailed analyses have to assess dose-response curves at different time points for abiraterone in those cell lines and the time course of development of possible abiraterone cross resistance.

Interestingly, enzalutamide resistant LAPC4 cells proliferate less under control conditions than under enzalutamide treatment. Moreover, enzalutamide resistant LAPC4 exhibit higher levels of nuclear AR in the presence of enzalutamide than without the drug. This observation may point to a switch from antagonistic to agonistic action of enzalutamide as described already for bicalutamide and may explain an enzalutamide withdrawal syndrome which was evident in a subset of patients [36]. In line with this hypothesis, Korpal et al. described an antagonistto-agonist switch in enzalutamide resistant LNCaP due to a F876L mutation of AR [7]. However, we found no AR mutation in our enzalutamide resistant LAPC4 cells. Future studies have to carefully investigate this issue.

\section{Conclusion}

In the present study we show for the first time the successful establishment of three different enzalutamide resistant cell lines, which provide an important tool for investigation of resistance mechanisms in cells with different AR statuses. We found that in these models enzalutamide resistance is not accompanied by $\mathrm{AR}$ mutations, while increased expression of full length and truncated AR as well as AR gene amplification might be involved in development of resistance. Furthermore, our results suggest that abiraterone treatment might be feasible in a subset of patients resistant to enzalutamide.

\section{MATERIAL AND METHODS}

\section{Cell culture and chemicals}

The human prostate cell lines LAPC4 (lymph node metastasis) were a gift from Dr. A. Cato (University of Karlsruhe, Germany). DuCaP (brain metastasis) were a gift from from Dr. J Schalken (Radboud University, Nijmegen, The Netherlands). The subline LNCaP Abl was previously established by our group after long term cultivation of LNCaP (lymph node metastasis) in steroid free medium as described earlier [15]. The identity of the used cell lines was confirmed by short tandem repeat analysis. LAPC4 and DuCaP cells were cultured in RPMI 1640 containing 10\% fetal bovine serum (FBS; PAA Laboratories) and $2 \mathrm{mM}$ glutamax (Thermo Fisher Scientific). LAPC4 were in addition supplemented with $1 \mathrm{nM}$ dihydrotestosterone (DHT). LNCaP Abl cells were grown in RPMI 1640 containing 10\% charcoal stripped FBS (HyClone, GE Healthcare) and $2 \mathrm{mM}$ glutamax. Androgen stimulation experiments were performed using $1 \mathrm{nM}$ of the synthetic androgen R1881 (Organon) dissolved in EtOH. Enzalutamide and abiraterone (both MedChemExpress) were dissolved in EtOH at a concentration of $1 \mathrm{mM}$. Bicalutamide (AstraZeneca) was dissolved in DMSO at a concentration of $5 \mathrm{mM}$.

\section{Generation of resistant cell lines}

Cell lines were cultured in the presence of increasing doses of enzalutamide or vehicle $(\mathrm{EtOH})$. Drug treatment was started using $0.2 \mu \mathrm{M}$ enzalutamide. Drug-containing medium was changed every third day. Cells were splitted when $80 \%$ confluency was reached. Enzalutamide concentration was increased when cells started to regrow in the presence of the drug at a growth rate similar to that of control cells until final concentrations (DuCaP, LAPC4: $8 \mu \mathrm{M}$; LNCaP Abl: $13 \mu \mathrm{M}$ ) were reached. Cells were then cultured for another 8 weeks in these conditions.

\section{Quantitative real time PCR (qRT-PCR)}

Total RNA was isolated using the RNeasy mini kit (Qiagen, Hilden, Germany) and cDNA synthesis was performed using iScript Select cDNA synthesis kit (Biorad). Taqman qRT-PCR was performed as described elsewhere [37]. Expression was normalized to the endogenous reference TATA-Box binding protein (TBP) (forward 5-CACGAACCACGGCACTGATT-3; reverse 5-TTTTCTGCTGCCAGTCTGGAC-3; probe 5-FAMTCTTCACTCTTGGCTCCTGTGCACA-TAMRA-3). The following primers and probes were used: $A R$ (Fwd: 5'-AGGATGCTCTACTTCGCCCC-3'; Rev: 5'-ACTGGCTGTACATCCGGGAC-3'; Probe: 5'-FAMTGGTTTTCAATGAGTACCGCATGCACA-TAMRA-3'), PSA (Fwd: 5'-GTCTGCGGCGGTGTTCTG-3'; Rev: 5'-TGCCGACCCAGCAAGATC-3'; Probe: 5'-FAMCACAGCTGCCCACTGCATCAGGA-TAMRA-3'). For FKBP5 (Hs01561006_m1) and KLK2 (Hs00428383_m1), a taqman gene expression assay (Applied Biosystems) was used according to the manufacturer's protocol. Detection of AR-V7 was performed by SYBR green real time PCR employing the Power Sybr green PCR master mix 
(Applied Biosystems). The following primer sequences were used at a final concentration of $400 \mathrm{nM}$ each: V7 forward: 5'-CGGAAATGTTATGAAGCAGGGATGA-3', V7 reverse: 5'- CTGGTCATTTTGAGATGCTTGCAAT - 3' [38]. Efficiency of primers was calculated as $108 \%$ using serial dilutions of a plasmid carrying AR-V7.

\section{Western blot}

Western blot was performed as previously described [37]. The following antibodies were used: anti-GAPDH (1:100000; Chemicon), anti-AR (N20; 1:500; Santa Cruz). As a positive control for truncated AR variant 7 band at 70 $\mathrm{kDa}$ size, a $\mathrm{VCaP}$ cell extract was included.

\section{Immunofluorescence}

Immunofluorescence was performed as described previously [39]. Briefly, cells were seeded in standard growth medium in 6 well plates containing glass coverslips. On the next day, medium was changed to medium supplemented with $10 \%$ charcoal stripped FBS (SF) including $1 \mathrm{nM} \mathrm{R} 1881,8 \mu \mathrm{M}$ enzalutamide or both, as indicated. After $24 \mathrm{~h}$, cells were fixed with $4 \%$ paraformaldehyde and permeabilized with PBS / 1\% BSA / $0.2 \%$ Triton X100. After a blocking step, cells were incubated with mouse anti-AR (Biogenex; 1:50) for 1 hour and subsequently probed with the labeled secondary antibody donkey anti mouse 555 (Invitrogen) for 1 hour. Cells were embedded using Vectashield mounting medium containing Dapi (Vector Laboratories). The cells were visualized using fluorescent microscopy on a Zeiss Axio Imager Z2 microscope.

\section{$\left[{ }^{3} \mathrm{H}\right]$ thymidine incorporation assay}

Cells were seeded in triplicates onto 96-well plates. On the next day, cells were treated with enzalutamide, abiraterone, bicalutamide or vehicle $(\mathrm{EtOH})$ as indicated. On day $5,25 \mu \mathrm{L} /$ well of diluted $\left[{ }^{3} \mathrm{H}\right]$ thymidine $(1 \mu \mathrm{Ci} /$ well) were added for $24 \mathrm{~h}$. DNA was harvested on 96-well filter plates (Perkin-Elmer). Scintillation fluid $(50 \mu \mathrm{L})$ was added and radioactivity was quantified using a Chameleon 5025 liquid scintillation counter (HVD Life Sciences).

\section{Viability assay}

Viability was assessed using WST reagent (Roche) according to the manufacturer's protocol.

\section{Reporter gene assay}

AR reporter gene assay was performed with ARnegative PC-3 cells in 96-well plate format employing a synthetic promoter composed of two androgen responsive elements and a TATA-box ((ARE) ${ }_{2}$ TATA) in framework of nanoluc reporter vector pNL1.1 [Nluc] (Promega). A PGK-promoter driven luciferase control vector (pGL4.53, Promega) was included for normalization. Per well, $30 \mathrm{ng}$ of each, reporter and normalization control vector and $4 \mathrm{ng}$ of AR-wild-type expression vector pSG5AR were mixed and complexed for $15 \mathrm{~min}$ with $0.2 \mu \mathrm{L}$ of transfection reagent (Viafect, Promega) in $3 \mu \mathrm{L}$ of transfection buffer and thereafter mixed with $50 \mu \mathrm{L}$ of $\mathrm{PC} 3$ suspended in medium supplemented with $3 \%$ charcoal-stripped FCS $\left(2 \times 10^{5}\right.$ cells $\left./ \mathrm{mL}\right)$. After an incubation for $30 \mathrm{~min}$ at room temperature cell suspension was transferred to the wells, R1881 (1 nM), enzalutamide $(10 \mu \mathrm{M})$ and vehicle were added and cells were incubated for $36 \mathrm{~h}$ before NanoLuc and firefly luciferase activities were measured using Chameleon 5025 instrument (HVD Life Sciences) and Nano-Glo Dual-Luciferase Assay (Promega) according to manufacturer's recommendations. Quadruplicate samples were measured for each treatment and nanoluc reporter gene activity was normalized to control luciferase activity.

\section{Sequencing of AR coding sequence}

cDNA, prepared as described above, was used to PCR-amplify 3 overlapping AR cDNA fragments covering the entire AR coding sequence $[40,41]$. cDNA fragments were purified using QIAquick PCR amplification kit (Qiagen) and sent for Sanger sequencing with appropriate sequencing primers (Microsynth) as described previously $[40,41]$. Sequences were aligned to NCBI AR Reference Sequence NM_000044.3 using APE-A plasmid editor (v2.0.45) and checked for mutations.

\section{Measurement of gene amplification}

Amplification of AR gene in parental, vehicle and EnzaR cell lines was assessed by duplex qPCR quantifiying AR (location Xq12, NCBI gene ID 367 ) in relation to POLG gene (polymerase gamma, location 15q25, NCBI gene ID 5428) in genomic DNA. Genomic DNA was isolated using QIAquick DNA isolation kit (Qiagen) and a duplex qPCR was performed with $20 \mathrm{ng}$ of DNA using primer/probe sets AR fw 5'-GACCTTAAAGACATCCTGAG-3', AR rev 5'CCCTAAGTAATTGTCCTTGG-3', AR probe FAM5'-CAACTCCTTCAGCAACAGCAGC-3' BHQ1 and POLG_fw 5'-AGAGCGTTACTCTTGGAC-3', POLG_ rev 5'-TCGGTCAAAGGAAACATTG-3', POLG probe YYE-5'-CACCACTAACTGCTCCTGCCA3'BHQ1 on ABI 7500 FAST real-time PCR instrument (Life Technologies). Primers and probe were used at a concentration of 800 and $100 \mathrm{nM}$, respectively. PCR efficiency was calculated as $105 \%$. The ratio AR/POLG DNA was calculated using the formula $2^{-\Delta c t}$ and normalized to male control DNA, harboring 1 copy of AR gene. 


\section{ACKNOWLEDGMENTS}

We thank Gabriele Dobler for help with cell culture and measurement of amplification and Christina Strobl and Alexandra Kaindl-Lindinger for help with cell line authentication. We thank Andrew Cato for providing LAPC4 cells and Jack Schalken for providing DuCaP cells.

\section{CONFLICTS OF INTEREST}

There are no conflicts to declare.

\section{GRANT SUPPORT}

We acknowledge the support of this study through funding from Krebshilfe Tyrol grant to IH, MUI start program to IH and FWF grant T 738-BBL to JH.

\section{Authors' contribution}

$\mathrm{IH}$ and $\mathrm{HK}$ designed the project; JH established long-term treated cell lines, designed and performed experiments and wrote the manuscript. MA, FH, PO and MP helped conducting experiments and interpreting results; WP performed cell line authentication; IH, HK and $\mathrm{ZC}$ helped designing experiments and writing the manuscript.

\section{REFERENCES}

1. Tran C, Ouk S, Clegg NJ, Chen Y, Watson PA, Arora V, Wongvipat J, Smith-Jones PM, Yoo D, Kwon A, Wasielewska T, Welsbie D, Chen CD, et al. Development of a second-generation antiandrogen for treatment of advanced prostate cancer. Science. 2009; 324:787-790.

2. Menon MP, Higano CS. Enzalutamide, a second generation androgen receptor antagonist: development and clinical applications in prostate cancer. Current oncology reports. 2013; 15:69-75.

3. Scher HI, Fizazi K, Saad F, Taplin ME, Sternberg CN, Miller K, de Wit R, Mulders P, Chi KN, Shore ND, Armstrong AJ, Flaig TW, Flechon A, et al. Increased survival with enzalutamide in prostate cancer after chemotherapy. The New England journal of medicine. 2012; 367:1187-1197.

4. Beer TM, Tombal B. Enzalutamide in metastatic prostate cancer before chemotherapy. The New England journal of medicine. 2014; 371:1755-1756.

5. Kim W, Ryan CJ. Androgen receptor directed therapies in castration-resistant metastatic prostate cancer. Current treatment options in oncology. 2012; 13:189-200.

6. Li Y, Chan SC, Brand LJ, Hwang TH, Silverstein KA, Dehm SM. Androgen receptor splice variants mediate enzalutamide resistance in castration-resistant prostate cancer cell lines. Cancer research. 2013; 73:483-489.

7. Korpal M, Korn JM, Gao X, Rakiec DP, Ruddy DA, Doshi S, Yuan J, Kovats SG, Kim S, Cooke VG, Monahan JE, Stegmeier F, Roberts TM, et al. An F876L mutation in androgen receptor confers genetic and phenotypic resistance to MDV3100 (enzalutamide). Cancer discovery. 2013; 3:1030-1043.

8. http://androgendb.mcgill.ca. The Androgen Receptor Gene Mutation Database

9. Gottlieb B, Beitel LK, Nadarajah A, Paliouras M, Trifiro M. The androgen receptor gene mutations database: 2012 update. Human mutation. 2012; 33:887-894.

10. Heidenreich A, Bastian PJ, Bellmunt J, Bolla M, Joniau S, van der Kwast T, Mason M, Matveev V, Wiegel T, Zattoni F, Mottet N, European Association of U. EAU guidelines on prostate cancer. Part II: Treatment of advanced, relapsing, and castration-resistant prostate cancer. European urology. 2014; 65:467-479.

11. Richards J, Lim AC, Hay CW, Taylor AE, Wingate A, Nowakowska K, Pezaro C, Carreira S, Goodall J, Arlt W, McEwan IJ, de Bono JS, Attard G. Interactions of abiraterone, eplerenone, and prednisolone with wild-type and mutant androgen receptor: a rationale for increasing abiraterone exposure or combining with MDV3100. Cancer research. 2012; 72:2176-2182.

12. van Soest RJ, van Royen ME, de Morree ES, Moll JM, Teubel W, Wiemer EA, Mathijssen RH, de Wit R, van Weerden WM. Cross-resistance between taxanes and new hormonal agents abiraterone and enzalutamide may affect drug sequence choices in metastatic castrationresistant prostate cancer. European journal of cancer. 2013; 49:3821-3830.

13. Antonarakis ES, Lu C, Wang H, Luber B, Nakazawa M, Roeser JC, Chen Y, Mohammad TA, Chen Y, Fedor HL, Lotan TL, Zheng Q, De Marzo AM, et al. AR-V7 and resistance to enzalutamide and abiraterone in prostate cancer. The New England journal of medicine. 2014; 371:1028-1038.

14. Karantanos T, Corn PG, Thompson TC. Prostate cancer progression after androgen deprivation therapy: mechanisms of castrate resistance and novel therapeutic approaches. Oncogene. 2013; 32:5501-5511.

15. Culig Z, Hoffmann J, Erdel M, Eder IE, Hobisch A, Hittmair A, Bartsch G, Utermann G, Schneider MR, Parczyk K, Klocker H. Switch from antagonist to agonist of the androgen receptor bicalutamide is associated with prostate tumour progression in a new model system. British journal of cancer. 1999; 81:242-251.

16. Veldscholte J, Berrevoets CA, Ris-Stalpers C, Kuiper GG, Jenster G, Trapman J, Brinkmann AO, Mulder E. The androgen receptor in $\mathrm{LNCaP}$ cells contains a mutation in the ligand binding domain which affects steroid binding characteristics and response to antiandrogens. The Journal 
of steroid biochemistry and molecular biology. 1992; 41:665-669.

17. Brooke GN, Parker MG, Bevan CL. Mechanisms of androgen receptor activation in advanced prostate cancer: differential co-activator recruitment and gene expression. Oncogene. 2008; 27:2941-2950.

18. Saramaki OR, Harjula AE, Martikainen PM, Vessella RL, Tammela TL, Visakorpi T. TMPRSS2:ERG fusion identifies a subgroup of prostate cancers with a favorable prognosis. Clinical cancer research. 2008; 14:3395-3400.

19. Hu R, Dunn TA, Wei S, Isharwal S, Veltri RW, Humphreys E, Han M, Partin AW, Vessella RL, Isaacs WB, Bova GS, Luo J. Ligand-independent androgen receptor variants derived from splicing of cryptic exons signify hormonerefractory prostate cancer. Cancer research. 2009; 69:16-22.

20. Taplin ME, Rajeshkumar B, Halabi S, Werner CP, Woda BA, Picus J, Stadler W, Hayes DF, Kantoff PW, Vogelzang NJ, Small EJ, Cancer and Leukemia Group BS. Androgen receptor mutations in androgen-independent prostate cancer: Cancer and Leukemia Group B Study 9663. Journal of clinical oncology. 2003; 21:2673-2678.

21. Marcelli M, Ittmann M, Mariani S, Sutherland R, Nigam R, Murthy L, Zhao Y, DiConcini D, Puxeddu E, Esen A, Eastham J, Weigel NL, Lamb DJ. Androgen receptor mutations in prostate cancer. Cancer research. 2000; 60:944-949.

22. Yamamoto Y, Loriot Y, Beraldi E, Zhang F, Wyatt AW, Nakouzi NA, Mo F, Zhou T, Kim Y, Monia BP, MacLeod AR, Fazli L, Wang Y, et al. Generation 2.5 antisense oligonucleotides targeting the androgen receptor and its splice variants suppress enzalutamide-resistant prostate cancer cell growth. Clinical cancer research. 2015; 21:1675-1687.

23. Linja MJ, Savinainen KJ, Saramaki OR, Tammela TL, Vessella RL, Visakorpi T. Amplification and overexpression of androgen receptor gene in hormone-refractory prostate cancer. Cancer research. 2001; 61:3550-3555.

24. Azad AA, Volik SV, Wyatt AW, Haegert A, Le Bihan S, Bell RH, Anderson SA, McConeghy B, Shukin R, Bazov J, Youngren J, Paris P, Thomas G, et al. Androgen Receptor Gene Aberrations in Circulating Cell-Free DNA: Biomarkers of Therapeutic Resistance in CastrationResistant Prostate Cancer. Clinical cancer research. 2015; 21:2315-2324.

25. Salvi S, Casadio V, Conteduca V, Lolli C, Gurioli G, Martignano F, Schepisi G, Testoni S, Scarpi E, Amadori D, Calistri D, Attard G, De Giorgi U. Circulating AR copy number and outcome to enzalutamide in docetaxel-treated metastatic castration-resistant prostate cancer. Oncotarget. 2016; 7:37839-37845. doi: 10.18632/oncotarget.9341.

26. Shiota M, Yokomizo A, Naito S. Increased androgen receptor transcription: a cause of castration-resistant prostate cancer and a possible therapeutic target. Journal of molecular endocrinology. 2011; 47:R25-41.
27. Efstathiou E, Titus M, Wen S, Hoang A, Karlou M, Ashe R, Tu SM, Aparicio A, Troncoso P, Mohler J, Logothetis CJ. Molecular characterization of enzalutamide-treated bone metastatic castration-resistant prostate cancer. European urology. 2015; 67:53-60.

28. Liu C, Lou W, Zhu Y, Nadiminty N, Schwartz CT, Evans $\mathrm{CP}, \mathrm{Gao}$ AC. Niclosamide inhibits androgen receptor variants expression and overcomes enzalutamide resistance in castration-resistant prostate cancer. Clinical cancer research. 2014; 20:3198-3210.

29. Nguyen HG, Yang JC, Kung HJ, Shi XB, Tilki D, Lara PN, Jr., DeVere White RW, Gao AC, Evans CP. Targeting autophagy overcomes Enzalutamide resistance in castration-resistant prostate cancer cells and improves therapeutic response in a xenograft model. Oncogene. 2014; 33:4521-4530.

30. Liu C, Zhu Y, Lou W, Cui Y, Evans CP, Gao AC. Inhibition of constitutively active Stat3 reverses enzalutamide resistance in $\mathrm{LNCaP}$ derivative prostate cancer cells. The Prostate. 2014; 74:201-209.

31. Arora VK, Schenkein E, Murali R, Subudhi SK, Wongvipat J, Balbas MD, Shah N, Cai L, Efstathiou E, Logothetis C, Zheng D, Sawyers CL. Glucocorticoid receptor confers resistance to antiandrogens by bypassing androgen receptor blockade. Cell. 2013; 155:1309-1322.

32. Pfeiffer MJ, Smit FP, Sedelaar JP, Schalken JA. Steroidogenic enzymes and stem cell markers are upregulated during androgen deprivation in prostate cancer. Molecular medicine. 2011; 17:657-664.

33. Loriot Y, Bianchini D, Ileana E, Sandhu S, Patrikidou A, Pezaro C, Albiges L, Attard G, Fizazi K, De Bono JS, Massard C. Antitumour activity of abiraterone acetate against metastatic castration-resistant prostate cancer progressing after docetaxel and enzalutamide (MDV3100). Annals of oncology. 2013; 24:1807-1812.

34. Noonan KL, North S, Bitting RL, Armstrong AJ, Ellard SL, Chi KN. Clinical activity of abiraterone acetate in patients with metastatic castration-resistant prostate cancer progressing after enzalutamide. Annals of oncology. 2013; 24:1802-1807.

35. Francini E, Petrioli R, Roviello G. No clear evidence of a clinical benefit of a sequential therapy regimen with abiraterone acetate and enzalutamide. Expert review of anticancer therapy. 2014; 14:1135-1140.

36. Rodriguez-Vida A, Bianchini D, Van Hemelrijck M, Hughes S, Malik Z, Powles T, Bahl A, Rudman S, Payne H, de Bono J, Chowdhury S. Is there an antiandrogen withdrawal syndrome with enzalutamide? BJU international. 2015; 115:373-380.

37. Puhr M, Santer FR, Neuwirt H, Susani M, Nemeth JA, Hobisch A, Kenner L, Culig Z. Down-regulation of suppressor of cytokine signaling- 3 causes prostate cancer cell death through activation of the extrinsic and intrinsic apoptosis pathways. Cancer research. 2009; 69:7375-7384. 
38. Yu Z, Chen S, Sowalsky AG, Voznesensky OS, Mostaghel EA, Nelson PS, Cai C, Balk SP. Rapid induction of androgen receptor splice variants by androgen deprivation in prostate cancer. Clinical cancer research. 2014; 20:1590-1600.

39. Hoefer J, Schafer G, Klocker H, Erb HH, Mills IG, Hengst L, Puhr M, Culig Z. PIAS1 is increased in human prostate cancer and enhances proliferation through inhibition of $\mathrm{p} 21$. The American journal of pathology. 2012; 180:2097-2107.
40. Culig Z, Hobisch A, Cronauer MV, Cato AC, Hittmair A, Radmayr C, Eberle J, Bartsch G, Klocker H. Mutant androgen receptor detected in an advanced-stage prostatic carcinoma is activated by adrenal androgens and progesterone. Molecular endocrinology. 1993; 7:1541-1550.

41. Culig Z, Klocker H, Eberle J, Kaspar F, Hobisch A, Cronauer MV, Bartsch G. DNA sequence of the androgen receptor in prostatic tumor cell lines and tissue specimens assessed by means of the polymerase chain reaction. The Prostate. $1993 ; 22: 11-22$. 